Article

\title{
Designing Flexibility and Adaptability: The Answer to Integrated Residential Building Retrofit
}

\author{
Giuliana Scuderi \\ Department of Civil Engineering, HZ University of Applied Sciences, Edisonweg 4, \\ 4382 NW Vlissingen, The Netherlands; scud0001@hz.nl
}

Received: 9 December 2018; Accepted: 8 January 2019; Published: 11 January 2019

\begin{abstract}
Speaking about building retrofit in Europe, the attention is often focused on the residential building stock built after the Second World War, which represents the $75 \%$ of the total number of buildings present on the territory. Recently many cities are encouraging campaigns of retrofit of the housing heritage built after the Second World War, since, in terms of cost, time, financing, consumption, and sustainability, the practice appears more convenient than building anew. To maximize the benefits of these retrofit campaigns, it is essential to promote multi-purpose and innovative strategies considering contemporarily architectural, functional and structural aspects. In the field of housing, in particular, it is necessary to develop new models able to answer to the new living style of a dynamic society. In fact, today as in the past, one of the downfalls of the housing sector is failing to recognize the human dimension within the designing process. This paper evaluates past architectural practices to achieve adaptability and flexibility in the residential sector and evaluate strategies for integrated retrofit based on two macro-areas: architectural/societal/functional and structural/technological/constructional.
\end{abstract}

Keywords: flexibility; adaptability; housing; building retrofit

\section{Introduction}

Speaking about building retrofit in Europe, the attention is often focused on the residential building stock, which represents in average the $75 \%$ of the total number of buildings present on the territory [1]. The European Commission stresses upon the diversity of the share: The $60 \%$ in Slovakia, Netherlands and Austria to more than $85 \%$ in Cyprus, Malta and Italy.

Most of this housing was built after WWII, when the most famous architects of the early 20th Century were involved in answering the shortage of decent and functional housing [2] by exploiting the new principles of industrialization and prefabrication [3].

Despite the great effort deployed in those experimentations, those architects failed in taking advantage of the technical and technological advances of the construction sector of the time [4], producing instead monotone and low quality mass housing and, later, suburban sprawl. Since then, mass and prefabricated housing has the negative connotation of renouncing to quality standards for the sake of cost and time.

Additionally, for the first time after the oil crisis in the 1970s and then again in the 1980s, residential buildings manifested serious architectural, functional and structural problems [5-7]. Today, obsolete buildings or those approaching disuse and demolition can be vital elements of the construction sector [8], either if demolished to recover floor area or if rehabilitated and/or reused [9].

If demolition and reconstruction grants safe houses with modern comforts, services and performances, in most of the cases the process requires 80 years to compensate the use of natural resources and the waste produced [10]. 
On the other hand, authors [11-13] agree on the benefits connected with the requalification of the existing buildings: Pre-existing elements and materials decrease the need of new resources and the construction process is faster, reducing the financing, the effects of inflation and risk.

The market of recovery is also important for the construction sector in general. In 2017, the construction sector recorded a growth of 4.1\% (EUROCONSTRUCT 2018/86), with Northwestern Europe leading the increase in market growth [14]. Market growth for Northwestern and Southern Europe combined is forecasted at 2.5\% a year on average in 2018-2022 [15]. However, if considering for instance energy consumption and pollution issues, new constructions represent today such a small percentage of the built heritage to be almost irrelevant [16]. Consequently, the theme of urban regeneration recently became popular, spanning from redevelopments on an urban or territorial scale to localized small-scale episodes of "urban acupuncture" [17]. All these experiences show the innovative attitude of European countries in promoting pilot projects and new strategies.

Among these experiences, recently many cities in Europe are encouraging campaigns of retrofit of the housing heritage built after the Second World War.

To maximize the benefits of these retrofit campaigns, it is essential to promote multi-purpose and innovative strategies considering contemporarily architectural, functional and structural aspects.

In the field of housing, in particular, it is necessary to develop new models able to answer to the new living style of a dynamic society living in a changing cityscape. In fact, today as in the past, one of the downfalls of the housing sector is failing to recognize the human dimension within the designing process. Human beings are incredibly flexible and adaptable and they desire buildings able to be adaptable as well, following their own individuality. As a consequence, if housing is conceived as a static object, it is destined to become inadequate and obsolescent.

Creating evolutionary and dynamic mechanisms in a residence is convenient also in a long-term vision because it decreases the necessity of costly renovations and it increases the life span of the building [18].

While the housing market is pushing towards having "static" buildings in order to maintain a constant demand [18], contemporary research should focus on designing changeable housing, investing in flexibility and adaptability as the new paradigms for a successful design and the natural evolution of architecture.

First of all, including adaptability means understanding that "the future is not finite, that change is inevitable, but that a framework is an important element in allowing that change to happen" [19]. The "framework" provides a loose-fit space that can be easily reconfigured in time by the user, who co-evolves with the space [20]. Secondarily, including flexibility means allowing different physical arrangements during the life cycle of the building [21]. Together these two principles can summarize the modification of the layout, the potential to incorporate new technologies, the possibility to change demographics or, in extreme cases, the change in the building function.

This paper aims at evaluating past architectural practices of adaptability and flexibility in the residential field, in order to evaluate if these can be suitable strategies for achieving integrated retrofit [22]. In particular, past experiences will be evaluated based on two macro-areas: architectural/societal/functional and structural/technological/constructional.

\section{Materials and Methods}

\subsection{The Cultural and Architectural Background of the Research}

Within the architectural scene after the Second World War, this research focuses on the Metabolists, a group of Japanese architects that developed the idea of a city that develops organically, and grow accordingly to the needs of their inhabitants [22]. The vision of this movement resulted in the creation of various architectural projects and urban plans with flexible and expandable structures, in which tradition, technology, human beings, and nature are harmoniously synthetized. "The philosophy of metabolic design is based on exchangeability, modular buildings, prefabricated parts and capsules. 
The units move, change or expand according to the needs of the individual, thereby creating organic growth" [23].

In this panorama, it starts to assume relevance, the plug-in idea, derived from Le Corbusier's design concept developed for the Unite d'Habitation in Marseilles [24]. In the 1960s, the Archigram's Peter Cook introduces the Plug-in City in which housing, office, and shop are all prefabricated modules that can be inserted in a mega structure with rail-mounted cranes. The modules are projected to be progressively updated to fit the latest technological developments and living standards. A self-refreshing city which changes with its own inhabitants.

In the same years, Freidman [25] creates the vision of a town based on a combination of fixed and movable parts. The fixed part is represented by the "spatial infrastructure", a three dimensional multi-level structural grid. The movable elements consist of all the horizontal and vertical partitions, which allow to create different spatial arrangements within the main structure.

Finally, in 1964, Archigram's Warren Chalk designed a tower of plug-in capsular dwellings, prefabricated modules to be attached to a central structural core, which grants accessibility and common facilities. This idea will be redeveloped by many architects, such as Kisho Kurokawa's Nakagin Capsule Tower in Tokyo (1972) or the Richard Rogers and Ove Arup' prototype of Industrialized Housing System (1991-1992).

These visionary ideas eventually resulted in some extreme projects, such as the recent Nomad skyscraper by D'Amico and Tesio [26], constituted by a fix grid frame where recyclable units can be inserted in order to respond to the temporary housing needs of the modern nomads.

The main concept developed in that period is that "modern life can no longer be defined in the long term and consequently cannot be contained within a static order of symbolic buildings and spaces" [27].

\subsection{Issue Connected with Energy Performance}

The housing sector consumes approximately the $40 \%$ of the energy consumed in the EU [1]. Energy in households is consumed for heating, cooling, domestic hot water system, cooking and appliances [1].

The older part of the building stock tends to consume more, contributing greatly to the high-energy use of the building sector [28]. Consequently, energy upgrade of the buildings built after the Second World War has huge potential in order to reach the European energy and sustainability target.

On the other hand, energy issues are often calculated towards the end of the design process, in the form of regulatory or voluntary certificates [29] mostly to be used for official and marketing purposes. However, the earlier the design decisions are made, the bigger the impact with lower cost, because the potential to influence substantial decisions related to construction and operating costs is the highest in the early design process [30].

Another fundamental limitation is that the retrofit strategies proposed by industry and research are still focused on local, project-based solution [31,32], while an integrated and holistic approach would allow more effective final solutions.

\subsection{Analysis of the State of the Art: The Working Sample}

Different examples of flexible residential housing were analyzed within this research. Following, the list of the buildings studies, classified for historical period. A more detailed description of the solutions can be found in Scuderi [33].

1945-1950s: The "baby boomers" and the post-war reconstruction

- Movable boxes, Yona Friedman, 1949

- Meudon, Jean Prouvè, France, 1950

- Jarnbrott Experimental housing, Tage and Anders William-Olsson, Sweden 1953

- Single-space house for four people, Gio Ponti, Italy 1957 
1960s-1970s: House expansion and standardized affordable mass housing

- Kallebäck Experimental Housing, Erik Friberger, Sweden, 1960

- The adaptable house, Development Group of the MHLG, UK, 1962

- $\quad$ Extendible houses, J.H. van den Broek, J.B. Bakema, The Netherlands 1963.

- Neuwil, Metron-Architekten AG, Switzerland, 1962-1965

- $\quad$ E.C.C.S. Steel Housing, J.H. van den Broek, J.B. Bakema, Netherlands, 1967

- Wohnhaus Kronsberger Stasse, Bernhard Binder and Stefan Polonyi, Germany, 1969

- Diagoon Houses, Architectuurstudio Herman Hertzberger, Netherlands, 1971

- Wohnanlage Genter Strasse, Otto Steidle and partner, Germany, 1972

- Metastadt, Metastadt-Planungsgesellschaft mbH, Germany, 1974

- Les Anticonformes, Les Frères Arsène-Henry, France, 1975

- Flexibo, Flaellestegnestuen, Denmark, 1976

- $\quad$ Molenvliet, Frans van der Werf, Werkgroep KOKON, Nethelands, 1977

- $\quad$ Alexandra road, Neave Brown, UK, 1969-1978

- $\quad$ Adelaide Road Estate, Greater London Concil, UK, 1979

1980s-1990s: Renovation, revitalization and urban sprawl

- Feßtgasse Housing, Ottokar Uhl, Austria, 1980

- Flexibele woningbouw, Volkshuisvesting Rotterdam, Netherlands, 1984

- Honor Oak Park, Walter Segal, Jon Broome and self-builders, UK, 1987

- Brandhöfchen, Kramm + Strigl, Germany, 1995

- Housing Graz-Straßgang, Riegeler Riewe Architects, Austria, 1994

- Kölner Brett, Brandlhuber and Kniess, Germany, 1999

- $\quad$ Ålekistevej, Hvidt and Mølgaard, Denmark, 1988

- Atelierhaus Sigle, Architekten Linie 4, Germany, 1998

- The Transformable Apartment, Mark Guard Architects, UK, 1996

2000s-present: Urban sustainability and housing affordability

- $\quad$ Silvertown, Ash Sakula, UK, 2004

- Flexible Housing in Almere, UN Studio, Netherlands, 2001

- Greenwich Millennium Village (II), Proctor and Matthews Architects, UK, 2001

- Fred, Kaufmann 96, Austria, 2000

\section{Results}

\subsection{Designing Flexibility: Architecture, Society and Function}

The study of the state of the art led to the definition of families of strategies to obtain flexibility and to respond to the need of the users in a long time and cost effective method.

- First strategy: Plug-in

This strategy describes the possibility given to an occupant to expand or change a space by "plugging-in" a new part, increasing the possibility of usage.

The modification can involve both horizontal and the vertical planes, and it should be planned already during the design phase, in order to define the best plan layout to accommodate additional units.

Ideally, the new spaces should be use the same accessibility patterns, without interferences with the natural illumination. 
A key issue is that the plugging-in process should not cause disruptions to the existing dwelling, blending into it. This strategy offers many alternatives and opportunities for the current and future inhabitants, increasing the marketability of the property.

- Second strategy: Sum and split

The technique considers the possibility to connect two individual adjacent spaces to form a single larger space, and vice versa. Multiple dwellings must be considered within this design process, in order to avoid dimensional limits.

Other important considerations are connected to accessibility, to the efficiency of openings in different plan configurations, and to the design of services able to minimize the expenses.

This approach is a convenient long-term strategy that provides flexibility and a variety of rental opportunities for different family units.

- Third strategy: Shared room

Two adjacent dwellings can also share a non-specific room, negotiating its use, ownership and responsibility over the time in relation to the actual needs.

This room is often a larger space that accommodates a small bathroom and kitchen, to be used separately or partially joined to the principal unit.

The disadvantage connected with this strategy is the possibility of conflicts between the two tenants, if both require the extra space or none of them needs.

- Fourth strategy: Movable walls

In this case, the space can be quickly and easily arranged and re-configured for new functions, on a daily basis or in a long-term vision.

The design of the elements must allow fast and easy changes: Panels must be designed to disappear in open configuration and they do not have to interact with any structural elements. It is necessary to consider the practicability of the solution because of the moving and sliding of wall panels influence the positioning of the furniture, and whether or not the furniture itself requires to be movable.

- Fifth strategy: Folding

The method allows the inhabitant to change the use of a room on a daily basis, hiding the elements of the furniture when not needed.

A successful design considers the folding elements as integrated completely in the dwelling, disappearing and appearing giving in any case a coherent layout to the space. In some cases, the folding element can be fixed but with multiple uses over the day and over time.

This technique is particularly efficient in very small dwellings.

- Sixth strategy: Unfinished space

In this space, the use has not been fully determined by the designer and can be defined by the inhabitants at any later date.

This space owns the potentialities for different possibilities, so the designer must think of the possible ways in which the space may be modified, and then he has to design the space accordingly.

- $\quad$ Seventh strategy: Neutral space

The strategy concerns providing unlabelled rooms. The occupants can decide the most beneficial use of each space.

The main strategy of functionally neutral rooms is to provide a number of equally sized rooms off a central hall or circulation space, with services possibly allocated to the smaller areas.

By removing the hierarchical order contained in the labelling of rooms each space becomes an independent entity which can be used according to the needs of the occupants, inevitably changing over time. 
An added benefit connected to functionally neutral rooms is that the same housing unit can be occupied by a variety of different user groups.

\subsection{Designing Flexibility: Structure, Technology and Construction}

Experiences have shown a significant correlation between the selection of a construction technique and the degree of flexibility achieved, so that most of the successful renovation projects resulted to rely on techniques able to allow additional interventions over the time with simple processes, in strong opposition with the standard practice, needing of specialised and multiple skills for any update [34].

Simple and robust construction techniques based on lightness and flexibility principles, with the possibility to obtain reversible and removable interventions, are today the most convenient way to apply modifications to an existing construction.

- First strategy: Dry-construction systems

A means to obtain flexibility is the selection of dry-construction systems, which reduce time and costs of construction, with less environmental impacts during construction and at the end of the useful life of the building organism, thanks to the high percentage of recovery of the individual components, assembled mechanically. The reversibility of lightweight dry construction processes confers also a greater life span to the building, in relation to the changing needs of the inhabitants [35].

- Second strategy: Structural optimization

Every single part of a construction must perform a function with well-defined and measurable standards.

Every component seeks for optimization, enhancing the lightness and the simplicity of the structure as a whole and exploiting the full potential of technologies, materials and design [35].

A good structure is the one able to respond to functional requirements balancing the efficiency and economy of the design, reducing the amount of material and the constructive complexity at the same time improving quality and optimization [36].

- Third strategy: Frames and grids

This strategy exploits technology to create structural systems, in form of expressed grid structures, able to accept further and progressive changes. These schemes require a service core, accessible and adaptable for different plant reconfigurations during which user activities should continue, preferably undisturbed.

The method can be used in multi-family residential and mixed-use projects-in new construction or for the retrofit of existing buildings. This is particularly advantageous in large-scale real estate interventions, where simultaneous design of base building and user level is impracticable. The basic principle is again the division between structural fixed elements, with a long-life span, and movable components with a shorter life cycle.

- Fourth strategy: A new model of prefabricated housing

Within this model developers work to offer tailored solutions to individuals, architects create thousands of unique environments, manufacturers become suppliers of components, builders become installers and, finally, users become designers of their own unique living space. This model follows the social trends towards individualization.

Contrary to the common belief, there is not necessarily a conflict between efficient production and variety of forms. In fact, the variety might be the logical outcome of efficient production [37]. Systems and components that are not any longer useful for one building may be re-installed in another building. At the same time, if systems or components cannot be re-used as such, the materials from which they are made can be disassembled and reused for the production of new components or systems. The latter principle complies with the cradle-to-cradle concept such as described by McDonough and Braungart [38]. 
Furthermore, it forms an extension of the concept of building manufacturing towards building re-manufacturing.

This principle implies a structural design that considers more carefully the materials used and the way in which components are joined, to allow reusability and disassembly.

- Fifth strategy: Self-building

People build individual homes for all sorts of reasons, but mainly because they want to create something tailored to their family's unique requirements; or something architecturally appealing in all manner of styles; or because they want to live in a home that they might not be able to afford on the open market. There is something uniquely rewarding about building a home for you and your family, it harks back to the most basic of human instincts. Nowadays, however, self-build homes are not just about shelter and security, they are about expressing yourself and your lifestyle. For many, self-build is a chance to create the life they have always dreamed of [39]. Self-builders create their homes through a variety of methods-and very few actually build it entirely themselves. The majority employ an architect to come up with the design of the new home and contract a builder to construct it; others use so-called 'package' companies to provide a one-stop solution. Many others find themselves managing building sites and dealing directly with planners, tradespeople and materials suppliers.

Self-build in its wider meaning is an ordinary practice in many developing countries. It is also common among certain religious communities or subcultures.

Over the years, self-builders have been at the forefront of advances in house design and technology, being responsible for the dramatic uptake in recent years in eco-features such as solar power and heat pumps; underfloor heating; open plan design and smart home technology. These features take many years to filter through to commercial housing developments.

\section{Discussion}

Probably the best-known constructional principle to facilitate flexibility in housing is that of Habraken, whose theory of 'supports' was developed in opposition to prevailing conditions in the Dutch housing sector of the 1960s, as well as to enable his ideas of user participation.

Habraken, and the current Open Building movement, emphasise the use of modern construction techniques and prefabricated elements (factory-produced columns, beams and floor elements), but also the separation of base building, infill systems and subsystems, and manufacture and design for ease of assembly and disassembly [20].

While Open Building today typically presents highly technical building method, flexibility can also be achieved through simple building materials such as timber, as exemplified in the work of Walter Segal.

As with Habraken, we see in Segal the use of a flexible technical system as a means to achieve a 'flexible' social end, with his seminal buildings of the 1960s founded first on a belief in the empowerment of the lay self-builder.

The least researched area of flexible housing is the financial side. Sense tells us that flexibility is more economic in the long term because obsolescence of housing stock is limited, but there is little quantitative data to substantiate this argument [34].

As the cost of housing and construction prices increase, prefabricated buildings hold the promise of greater economy than their site built counterparts enhancing also quality control.

Even if Metabolism buildings were not built for economy per se, the $100 \mathrm{sq}$. $\mathrm{ft}$. capsules used by Kurokawa in the Nakagin Capsule Tower were said to be roughly the price of a Toyota Corolla [40].

At the same time, the perception of affordability in prefabricated buildings has come with the negative perception of inferior quality. The only way to get over this problem is to show that implementing flexibility adds value to the property and so it can command a higher price for little, if any, extra investment [34]. 
Industry always focuses on producing a fixed small number of products, produced on a mass scale for economic purpose. The most well know example is Ford Model T, which in the beginning only was produced in one variant, with Ford's emblematic quote saying: "you can have all the colours you want as long as it is black" [41].

Nevertheless even the car manufacturing has evolved over the years and by using a product platform, the customer can design his own car. This capability of delivering customer tailored cars increases the customers' perceived value of the product as unique, while the company still can exploit the economy of scale of mass production [41].

A key point in this process is the shift from a "demand-driven supply" towards a "supply-driven demand" [42]. In the construction field, usually suppliers react to the demand of the clients, while industry suggests that the suppliers should take the initiative, providing to the client a set of options to select among the available products [41].

Allying flexibility with progressive and industrialized technologies, framing is the most appropriate form of construction to deal with the differing needs of the occupants, allowing a selection of possible finishing and plan options. This gives great advantages during the construction process, because it allows greater customization and individualization of the space, but also at a later stage, giving the possibility to change the layout of a unit according to changes within a family, without large modification costs.

A recurring question is also the selection between low-tech and high-tech solutions, and in particular, the definition of which one is more suited to achieve a sustainable development of architecture and urban design. A certain tendency towards a low-tech approach can be discerned amongst many architects in practice and in research, but it seems more grounded on an emotional than intellectual level. This development is somehow fascinating and, at the same time, somewhat disconcerting for a society which depends so much on technology in everyday life [43].

Modularity in this sense is efficient and completely different from the uniformity of the mass housing, which alone was not able to grant industrialized methods.

In addition, the social trend towards customization of the production, transforms the demand for function more and more individualized and a bigger demand for complexity and variety is promoting the introduction of architectural components with shorter life cycle [18].

In this optic, prefabricated and optimized components are convenient for large-scale interventions, not giving limitation in terms of architectural characteristics and performances.

The final objective is to use flexible technical systems to achieve a flexible social dimension, with the final objective of self-construction, following the recent trend for the technical solution to become more and more an instrument of the community.

A change in the user typology is happening because of the disaggregation of the traditional family, for the different forms of social mobility and for the emergence of modern forms of nomadism. This phenomenon opens new considerations about the current building and urban standards, which need to be updated in order to respond to the requirements of an unspecified group of users that changes over the time and belongs to different social and cultural realities.

In the field of social housing, there is the necessity to develop model more prone to answer to the new way of living of a dynamic user and to reproduce the pattern of the changing city: The traditional "room" has given way to the "fields", able to promote higher permeability in both private and collective life. Another option for the architect is to design spaces with adjustable configuration or equipped walls able to rationalize the space in different ways along the time within a permanent or a temporary structural frame.

When the dwellings are able to perform rapid and continuous modification, adapting also to different users, it is possible to define a condition of "temporariness of use" [44].

If the buildings are not conceived anymore as static and unmodifiable objects, at the same time the interventions of modification and upgrading should not be expensive in terms of time and economic 
and material resources: The design of the intervention should promote velocity, lightness, safety and recyclability [45] other than reversibility and flexibility.

The analysis of the state of the art showed as lightweight interventions achieved using dry stratified construction technologies of structure/cladding/finishing, are a widespread approach to renovation and requalification. These types of intervention overcomes the necessity to relocate the dwellers during the construction process and they are less problematic for the structural capacity of the existing building.

\section{Conclusions}

The selection of the most suitable strategy depends on several factors, such as the structural typology and technology of the buildings, its historical and functional importance, and the socio-economic issues connected with the presence of serious damages and obsolescence.

Typically, the ratio between the costs and the performances achieved is determinant for the definition of the appropriate retrofit program: synergetic operations should improve the overall characteristics of the buildings, at the same time reducing the ancillary construction expenses.

If one method of achieving flexibility in housing is through the appropriate design of the plan, another is through the deployment of technology, considered as the complex of construction techniques, structural solutions, and servicing strategies.

Clearly, these two approaches are not mutually exclusive but usually they are used in combination to obtain a flexible residential project.

The actual problem arises when the emphasis shifts to the technical and constructional aspects of social housing, and away from the more socially grounded implications of flexibility. When techniques becomes an obsession, then technology becomes an end instead of a mean to reach an end. In this way, the technologies of flexibility lead to constructions where the technical aspects overrides issues of design and social occupation.

The solution is instead to use technology to create a framework for flexible housing to develop, abandoning the idea of a strict determinism and allowing a certain degree of "controlled freedom".

The research project led to the definition a new external structural envelope, called "adaptive exoskeleton".

The exoskeleton, as an enclosing capsule, can protect and support the existing building, which can be preserved and enhanced in terms of performance, safety, structural behavior and aesthetic quality. The exoskeleton defines external appearance and thermal regulation, adapting to environmental conditions, so it has all the architectural, functional and structural properties that can describe a structural envelope.

In the animal world, the exoskeleton is adaptive because it can adjust and modify in the time in order to respond to the growth of an insect, in the same way it is possible to imagine a new model for social housing, changing over time to respond to the new requirements of the user and of the market.

The technological device defined "adaptive exoskeleton", has been developed as a structural system morphologically comparable to a stiffening framework, external to the existing building and collaborating with it to optimize the structural response and the energetic performances, and to improve the quality of the internal spaces. This is a technological superstructure that includes new services and, eventually, seismic devices.

The "adaptive exoskeleton" exploits dry and reversible technological solutions, in a perspective of resource saving and recycling of construction materials, in order to suggest a concrete alternative to the demolition of obsolescent buildings. New independently designed "objects" (rooms, greenhouses, winter gardens, balconies, etc.) can be inserted inside the structural frame avoiding expensive modification works. In occasion of typological renewal of the entire building, new distributive elements can be then easily added. The realization of new elevations (with new residential units or common structures), if sold or rented, could cover the costs of the retrofit intervention. 
This practice can be used in different geographical, climate and urban contexts because, beside the steel frame, it grants absolute freedoms in the selection of the materials, performances and aesthetical features.

The final objective of the "adaptive exoskeleton" is to prolong the life cycle of the artefact thanks to the progressive adaptation, leading to the reduction of the environmental impact of the building itself distributed over a longer time span.

Further research about possible applications and practical considerations are needed.

Funding: This research received no external funding.

Acknowledgments: The author acknowledges the technical and theoretical support provided by the University of Trento (Italy) and the University of Brescia (Italy).

Conflicts of Interest: The author declares no conflict of interest.

\section{References}

1. Economidou, M.; Atanasiu, B.; Despret, C.; Maio, J.; Nolte, I.; Rapf, O. Europe's Buildings under the Microscope. A Country-by-Country Review of the Energy Performance of Buildings; Buildings Performance Institute Europe (BPIE): Brussels, Belgium, 2011; pp. 35-36.

2. Corbusier, L. Towards a New Architecture; Courier Corporation: North Chelmsford, MA, USA, 1931.

3. Larson, K.; Intille, S.; McLeish, T.J.; Beaudin, J.; Williams, R.E. Open source building-Reinventing places of living. BT Technol. J. 2004, 22, 187-200. [CrossRef]

4. Herbert, G. The Dream of the Factory-Made House: Walter Gropius and Konrad; MIT Press: Cambridge, MA, USA, 1984.

5. Power, A. Estates on the Edge: The Social Consequences of Mass Housing in Northern Europe; Macmillan: London, UK, 1997.

6. Andersen, H.S. Urban Sores. On the Interaction between Segregation, Urban Decay and Deprived Neighbourhoods; Ashgate: Farnham, UK, 2003.

7. Murie, A.; Knorr-Siedow, T.; van Kempen, R. Large Housing Estates in Europe: General Developments and Theoretical Backgrounds; Urban and Regional Research Centre, Faculty of Geosciences, Utrecht University: Utrecht, The Netherlands, 2003.

8. Chusid, M. Once is Never Enough. In Building Renovation; Springer: Heidelberg, Germany, 1993; pp. 17-20.

9. Langston, C.; Lauge-Kristensen, R. Strategic Management of Built Facilities; Routledge: Abingdon, UK, 2013.

10. Preservation Green Lab. The Greenest Building: Quantifying the Environmental Value of Building Reuse; National Trust for Historic Preservation: Seattle, WA, USA, 2011.

11. Johnson, A. Rehabilitation and re-use of existing buildings. In Building Maintenance and Preservation: A Guide to Design and Management, 2nd ed.; Mills, E.D., Ed.; Architectural Press: Oxford, UK, 1996; pp. 209-230.

12. Langston, C.; Wong, F.K.; Hui, E.C.; Shen, L.Y. Strategic assessment of building adaptive reuse opportunities in Hong Kong. Build. Environ. 2008, 43, 1709-1718. [CrossRef]

13. Egbelakin, T.; Wilkinson, S. Factors affecting motivation for improved seismic retrofit implementation. In Proceedings of the Australian Earthquake Engineering Conference (AEES), Ballarat, Australia, 21-23 November 2008.

14. Deloitte. European Construction Monitor 2017-2018: A Looming New Construction Crisis? Deloitte: London, UK, 2018.

15. Construction Intelligence Center. Global Construction Outlook to 2022; Construction Intelligence Center: London, UK, 2018.

16. Jaretti, S. Riflessioni sul riuso del patrimonio edilizio globale. In Riuso edilizio e rigenerazione urbana, innovazione e partecipazione; Lombardi, P., Ed.; Celid: Turin, Italy, 2008.

17. Lerner, J. Urban Acupuncture; Island Press: Washington, DC, USA, 2014.

18. Till, J.; Schneider, T. Flexible housing: The means to the end. Archit. Res. Q. 2005, 9, 287-296. [CrossRef]

19. Kronenburg, R. Flexible: Architecture that Responds to Change; Laurence King: London, UK, 2007.

20. Kendall, S.H.; Teicher, J. Residential Open Building; Routledge: Abingdon, UK, 2010.

21. Groak, S. The Idea of Building: Thought and Action in the Design and Production of Buildings; Taylor \& Francis: Abingdon, UK, 2002. 
22. Acharya, L. Flexible Architecture for the Dynamic Societies: Reflection on a Journey from the 20th Century into the Future. Master Thesis, Universitetet i Tromsø, Tromsø, Norway, 2013.

23. Echavarria, P. Portable Architecture and Unpredictable Suroundings; Links International: Hong Kong, China, 2004.

24. Frampton, K. Modern Architecture: A Critical History; Oxford University Press: Oxford, UK, 1980.

25. Friedman, Y. Architecture Mobile; ArchEyes: Madrid, Spain, 1960.

26. D'Amico, A.; Currà, E. Urban Resilience and Urban Structure: Vulnerability Assessment of Historical Italian Towns. In Proceedings of the ANDROID Residential Doctoral School in Disaster Resilience 2014, Salford Quay, UK, 8-11 September 2014.

27. Rogers, R. Cities for a Small Planet; Faber \& Faber: London, UK, 1997.

28. Itard, L. Towards a Sustainable Northern European Housing Stock: Figures, Facts, and Future; IOS Press: Amsterdam, The Netherlands, 2008; Volume 22.

29. Dakwale, V.A.; Ralegaonkar, R.V.; Mandavgane, S. Improving environmental performance of building through increased energy efficiency: A review. Sustain. Cities Soc. 2011, 1, 211-218. [CrossRef]

30. Bogenstatter, U. Prediction and optimization of life-cycle costs in early design. Build. Res. Inf. 2000, 28, 376-386. [CrossRef]

31. Di Giulio, R.; Bozinovski, Z.; Verhoef, L.G. Cost C16, Improving the Quality of Existing Urban Building Envelopes: Structures; IOS Press: Amsterdam, The Netherlands, 2007; Volume 3.

32. Nemry, F.; Uihlein, A.; Colodel, C.M.; Wetzel, C.; Braune, A.; Wittstock, B.; Hasan, I.; Kreißig, J.; Gallon, N.; Niemeier, S.; et al. Options to reduce the environmental impacts of residential buildings in the European Union-Potential and costs. Energy Build. 2010, 42, 976-984. [CrossRef]

33. Scuderi, G. Adaptive Exoskeleton for the Integrated Retrofit of Social Housing Buildings. Ph.D. Thesis, University of Trento, Trento, Italy, 2017.

34. Schneider, T.; Till, J. Flexible housing: Opportunities and limits. Archit. Res. Q. 2005, 9, 157-166. [CrossRef]

35. Scuderi, G. Adaptive building exoskeletons: A biomimetic model for the rehabilitation of social housing. ArchNet-IJAR Int. J. Archit. Res. 2015, 9, 134-143. [CrossRef]

36. Dooley, S. The Development of Material-Adapted Structural Form. Ph.D. Thesis, No. 2986, École polytechnique fédérale de Lausanne, Lausanne, Switzerland, 2004.

37. Habraken, N.J. The control of complexity. Places 1987, 4.

38. McDonough, W.; Braungart, M. Cradle to Cradle: Remaking the Way We Make Things; MacMillan: London, UK, 2010.

39. Giddens, A. Modernity and Self-Identity: Self and Society in the Late Modern Age; Stanford University Press: Palo Alto, CA, USA, 1991.

40. Russell, S.R. Metabolism Revisited: Prefabrication and Modularity in 21st Century Urbanism; University of South Florida: Tampa, FL, USA, 2008.

41. Thuesen, C.L.; Claeson, C.C. The Long Tail and Innovation of New Construction Practices: Learning Points from Two Case Studies. In Open Building Manufacturing Key Technologies, Applications, and Industrial Cases; ManuBuild: Rotherham, UK, 2009; pp. 49-64.

42. Ridder, H.D.; Vrijhoef, R. From demand-driven supply towards supply-driven demand in construction: A "living building" experiment. In Proceedings of the 3rd International SCRI Symposium, Delft, The Netherlands, 3-4 April 2006; Hughes, W., Ed.; pp. 530-542.

43. Cody, B. The Role of Technology in Sustainable Architecture. Wolkenkuckucksheim, Internationale Zeitschrift zur Theorie der Architektur 2014, 19, 239-249.

44. Bennicelli Pasqualis, M.G. Case temporanee. Strategie innovative per l'emergenza abitativa post-terremoto. In Collana Ricerche di tecnologia dell'architettura, 1st ed.; Franco Angeli: Milan, Italy, 2014.

45. Zambelli, E. Ristrutturazione e trasformazione del costruito; Il Sole 24 Ore: Milan, Italy, 2004.

(c) 2019 by the author. Licensee MDPI, Basel, Switzerland. This article is an open access article distributed under the terms and conditions of the Creative Commons Attribution (CC BY) license (http:/ / creativecommons.org/licenses/by/4.0/). 